\title{
Cognitive functioning in adolescents with migraine
}

\author{
Melissa Andréia Costa-Silva ${ }^{1}$, Ana Carolina de Almeida Prado², \\ Leonardo Cruz de Souza², Rodrigo Santiago Gomez ${ }^{1}$, Antônio Lúcio Teixeira ${ }^{1,2}$
}

\begin{abstract}
Although migraine is highly prevalent in children and teenagers, it often goes undetected in these patients, resulting in underdiagnosis and inadequate treatment. Several studies have investigated cognitive changes in adults with migraine. However, there are few studies focusing on children and adolescents. Objective: To investigate cognitive performance of adolescents with migraine. Methods: Twenty-eight adolescents diagnosed with migraine and twenty-six individuals without a history of headache were recruited for the study. All participants were evaluated using standardized neuropsychological tests. Results: Adolescents with migraine had worse performance on tests evaluating short- and long-term verbal memory, attention, executive function, and speed of processing information than controls. Conclusion: Cognitive dysfunction is common in adolescents with migraine. Since the cognitive deficits found in adolescents with migraine are similar to those reported in adults with migraine, cognitive impairment seems to persist throughout life. Key words: migraine, neuropsychology, adolescents, cognitive dysfunction, neuropsychological assessment.
\end{abstract}

\section{FUNCIONAMENTO COGNITIVO EM ADOLESCENTES COM MIGRÂNEA}

RESUMO. Apesar de apresentar uma prevalência alta em crianças e adolescentes, nem sempre a migrânea é corretamente identificada nessa faixa etária, o que resulta em tratamentos inadequados e ineficazes. Vários estudos investigaram disfunções cognitivas associadas à migrânea em adultos. No entanto, poucos foram direcionados às crianças e aos adolescentes. Objetivo: Investigar o funcionamento cognitivo de adolescentes com migrânea. Métodos: Participaram do estudo 28 adolescentes diagnosticados com migrânea e 26 controles. Os participantes foram avaliados através de testes neuropsicológicos padronizados. Resultados: Os adolescentes com migrânea apresentaram pior desempenho que controles em testes que avaliaram memória verbal de curto e de longo prazo, atenção, funções executivas, velocidade de processamento. Conclusão: Disfunção cognitiva é comum em adolescentes com migrânea. Os resultados apontam para a persistência dos prejuízos cognitivos ao longo da vida, uma vez que os prejuízos encontrados nos adolescentes são semelhantes aos encontrados em adultos com migrânea.

Palavras-chave: migrânea, neuropsicologia, adolescentes, disfunção cognitiva, avaliação neuropsicológica.

\section{INTRODUCTION}

Teadache is a symptom often present durof the most frequent complaints in pediatric offices. Despite this, the condition is often underdiagnosed, resulting in inadequate treatment. ${ }^{1}$ Migraine is highly prevalent among children and adolescents, affecting approximately $10 \%$ of all teenagers aged between $10-$ and $18 .^{1-3}$
Several studies have indicated cognitive changes in patients with migraine. ${ }^{4-9}$ There is evidence that adults with migraine may present deficits in attention, processing speed (reaction time), verbal memory, working memory, and verbal skills. ${ }^{4-9}$ Regarding other cognitive domains, such as visual memory and visuospatial/constructional skills, results are more conflicting. ${ }^{5}$ Few studies have assessed the impact of migraine parameters, such as

This study was conducted at the Laboratory of Medical Investigation, School of Medicine, Federal University of Minas Gerais, Belo Horizonte, Brazil.

${ }^{1}$ Headache Clinic, University Hospital, Federal University of Minas Gerais, Belo Horizonte, Brazil. ${ }^{2}$ Neuroscience Division, Interdisciplinary Laboratory of Medical Investigation, School of Medicine, Federal University of Minas Gerais, Belo Horizonte, Brazil.

Antônio Lúcio Teixeira. Laboratório Interdisciplinar de Investigação Médica / Sala 281 / Faculdade de Medicina / UFMG - Av. Prof. Alfredo Balena, 190 - $30130-$ 100 Belo Horizonte MG - Brazil. E-mail: altexr@gmail.com

Disclosure: The authors report no conflits of interest

Received November 24, 2015. Accepted in final form January 26, 2016 
episode frequency and duration, on cognitive performance, and results have failed to show any significant influence of these factors. ${ }^{4-6,10-12}$

Scant information is available regarding the impact of migraine on the cognition of children and adolescents. ${ }^{4}$ A previous study involving children with migraine aged 7 to 11 years found no global intelligence or visual-motor skill deficits, but identified short and long-term memory impairments. ${ }^{13}$ Inhibition deficits, impairment in speed of processing information, and in selecting and shifting attention were also reported in children suffering from migraine. ${ }^{14}$ These findings may partly explain the complaints related to poor academic performance in migraine subjects. ${ }^{15}$

Considering that childhood and adolescence are pivotal periods for appropriate schooling, and that cognitive deficits related to migraine may interfere with academic performance, thorough investigation of cognitive impairment in migraine subjects is crucial for subsequent follow-up by physicians.

The goals of the present study were: [1] to compare the cognitive performance of children and adolescents with migraine against performance of subjects without neurological disorders; and [2] to identify the neuropsychological tests which are sensitive to the cognitive alterations associated with migraine.

\section{METHODS}

Subjects. Fifty-four subjects aged 10 to 18 years were recruited for this study. Twenty-eight patients (22 women, 6 men) diagnosed with migraine (according to the Headache Society criteria) ${ }^{16}$ attended the headache service at the Neurology Service of the Federal University of Minas Gerais. Twenty-six individuals ( 19 women, 7 men) without a history of headache episodes were recruited from friends and family members of patients to ensure socioeconomic status matching.

Exclusion criteria for all subjects were as follows: [1] presence of headache, except migraine in the patient group; [2] history of head trauma; [3] history of any psychiatric disorder; [4] and history of other clinical conditions (concomitant disease). All subjects were examined by both a neurologist and a psychiatrist who also assessed participants' ability to understand the cognitive tests. If eligible, patients and controls were subjected to neuropsychological evaluation. All patients were free of pain and migraine effects during the neuropsychological evaluation session. No patients were in use of prophylactic medication.

Instruments. Neuropsychological evaluation was perf- ormed by a trained neuropsychologist (MACS). Episodic memory and learning were evaluated by the Rey Auditory Verbal Learning Test (RAVLT). The Trail-Making Test (A and B) (TMTa and TMTb) and the Stroop Test (ST) were used to evaluate executive functions. The Verbal Fluency Test (VFT) was administrated to assess language abilities. These instruments are traditional neuropsychological tests and have been widely used in neuropsychological assessment of children and adolescents with migraine. ${ }^{10-14}$

All tests were administrated within a single session. Informed consent was obtained from children and adolescents' parents or guardians. The study was approved by the Ethics Committee of the Federal University of Minas Gerais (COEP/UFMG).

Statistical analysis. Variables were checked for normality with the Kolmogorov-Smirnov test. For statistical analyses, the Chi-Square test was employed to compare categorical variables. As continuous data have a parametric distribution, Student's t-tests were used to compare control vs. migraine groups. The significance level was $<0.05$. All statistical analyses were performed using the Statistical Package for Social Sciences (SPPSS version 11.5).

\section{RESULTS}

There were no differences in age, sex and education between groups (Table 1 ).

Neuropsychological assessment showed significant differences between groups in short-term and long-term verbal memory (RAVLT), attention and executive functions (ST and TMT) and speed of processing information and visuomotor tracking and selective attention (TMTa and TMTb) (Table 2). Subjects with migraine performed worse than controls on all tests.

Regarding RAVLT, migraine patients had significantly lower scores than control subjects. This result indicates changes in verbal memory and cued recall and recognition of verbal stimuli. Significant differences were detected in visuomotor selective attention and speed of

Table 1. Descriptive data.

\begin{tabular}{lccccc}
\hline & \multicolumn{2}{c}{ Migraineurs } & \multicolumn{2}{c}{ Controls } & p \\
\hline Sample size & \multicolumn{2}{c}{28} & \multicolumn{2}{c}{26} \\
\hline Gender (\% female) & \multicolumn{2}{c}{78.57} & \multicolumn{2}{c}{73.07} & 0.75 \\
\hline & Mean & SD & Mean & SD & p \\
\hline Age (years) & 14.39 & 2.6 & 14.58 & 2.43 & 0.79 \\
\hline Education (years) & 7.79 & 2.42 & 7.88 & 2.28 & 0.87 \\
\hline
\end{tabular}


Table 2. Performance on neuropsychological tests

\begin{tabular}{|c|c|c|c|c|}
\hline Test & & $\begin{array}{l}\text { Controls } \\
\text { Mean (SD) }\end{array}$ & $\begin{array}{l}\text { Migraineurs } \\
\text { Mean (SD) }\end{array}$ & p \\
\hline \multirow[t]{10}{*}{ RAVLT } & $\mathrm{A} 1^{*}$ & $7.19(1.93)$ & $6.00(1.41)$ & 0.012 \\
\hline & $\mathrm{A} 2^{*}$ & $10.62(1.79)$ & $9.14(2.30)$ & 0.012 \\
\hline & $A 3^{*}$ & $12.50(1.27)$ & $10.89(2.00)$ & 0.001 \\
\hline & $\mathrm{A} 4^{*}$ & $12.96(1.53)$ & $11.64(2.14)$ & 0.013 \\
\hline & $A 5^{*}$ & $13.92(1.54)$ & $12.11(2.06)$ & 0.001 \\
\hline & $\Sigma A 1 A 5^{*}$ & $57.19(6.24)$ & $49.79(8.48)$ & 0.001 \\
\hline & $\mathrm{B} 1^{*}$ & $7.04(1.21)$ & 5.93 (1.78) & 0.011 \\
\hline & $A 6^{*}$ & $12.69(2.18)$ & $10.14(2.41)$ & 0.000 \\
\hline & $A 7^{*}$ & $13.04(1.68)$ & $9.79(2.94)$ & 0.000 \\
\hline & Recognition* & $14.62(0.57)$ & $13.79(1.75)$ & 0.025 \\
\hline \multirow[t]{4}{*}{ Trail-Making Test } & Trail A (time, s) ${ }^{\star}$ & $30.50(8.08)$ & 40.04 (18.65) & 0.02 \\
\hline & Trail A (errors) & $0.62(0.94)$ & $0.32(0.61)$ & 0.176 \\
\hline & Trail B (time, s) ${ }^{\star}$ & 77.19 (34.72) & 110.36 (68.89) & 0.032 \\
\hline & Trail B (errors) & $0.88(1.24)$ & $1.21(1.28)$ & 0.344 \\
\hline \multirow[t]{6}{*}{ Stroop Test } & Dots (time, s) ${ }^{\star}$ & $14.19(2.59)$ & $16.04(2.84)$ & 0.016 \\
\hline & Dots (errors) & $0.54(0.81)$ & $0.68(0.90)$ & 0.553 \\
\hline & Words (time, s) & $17.31(3.96)$ & $19.14(4.34)$ & 0.112 \\
\hline & Words (errors) & $0.31(0.47)$ & $0.32(0.72)$ & 0.935 \\
\hline & Colors (time, s) & $26.31(4.96)$ & $29.29(7.43)$ & 0.092 \\
\hline & Colors (errors) & $1.85(1.78)$ & $1.32(1.41)$ & 0.235 \\
\hline \multirow[t]{5}{*}{ Verbal Fluency Test } & $\mathrm{F}$ & 11.69 (3.69) & $11.14(2.82)$ & 0.54 \\
\hline & $A$ & $10.08(3.68)$ & 9.39 (2.98) & 0.45 \\
\hline & S & $9.58(3.26)$ & $9.64(3.12)$ & 0.94 \\
\hline & $\Sigma$ FAS & $31.38(9.12)$ & 30.14 (7.64) & 0.589 \\
\hline & Animals* & $18.15(4.79)$ & $14.71(4.36)$ & 0.008 \\
\hline
\end{tabular}

${ }^{*} \mathrm{p}<.05$

processing information between groups, as measured by reaction time (time in seconds) on the TMTa and TMTb. On the TMT, there were no differences in error rates between groups. Migraineurs also scored significantly lower on the ST than controls. There were no significant differences in word reading or ink color naming between groups. Lastly, regarding the VFT, patients with migraine displayed lower performance in the animals category. There were no significant differences in phonemic verbal fluency (FAS test).

\section{DISCUSSION}

Patients with migraine had poorer cognitive performance on neuropsychological testing than controls. This result supports previous findings showing that children and adolescents with migraine have impaired short- and long-term verbal memory, speed of processing information, and selective and divided attention. . $^{13,14,17,18}$

We observed that teenagers with migraine had verbal memory and learning impairments. Migraineurs are more affected by distractors during the learning process and have difficulties in recognition and recall. The poor test performance of migraineurs suggests deficits during registration, consolidation, and recall of verbal stimuli. These deficits are associated with changes in the ability to organize thoughts and to use strategies to search for information. The impairment in short- and long-term memory in children with migraine may be linked to learning difficulties. ${ }^{13}$

We found significant differences between groups for 
execution time on the TMT where migraineurs took longer to complete the test. Similar results have previously been reported. ${ }^{14}$ The TMT measures executive functioning and is associated with selective and divided attention, speed of processing information, and visuomotor tracking. Deficits in visuomotor tracking and selective attention are consistent with the available data on adults ${ }^{8}$ and children ${ }^{17}$ with migraine, but one study found no significant differences in sequential and simultaneous information processing between children with migraine and controls. ${ }^{19}$ Calandre et al. ${ }^{8}$ found differences only in reaction time between migraineurs and controls. To reconcile these findings, it is tempting to hypothesize that the speed of information processing might be the first sign of cognitive dysfunction in migraine. Over time, other cognitive domains may be progressively compromised. Interestingly, visuomotor processing speed has been reported to be one of the main deficits associated with white matter abnormalities. These are frequent unspecific findings described in brain magnetic resonance imaging studies of patients with migraine. ${ }^{8}$

The neurochemical and molecular substrates related to cognitive alterations in migraine are not yet fully understood. Neuroimaging studies have found associations between white matter abnormalities and headache frequency in adults. ${ }^{20-22}$ Moreover, neurotransmitters known to be involved with cognition such as dopamine, noradrenaline, and glutamate, seem to play a key role in the pathophysiology of migraine. ${ }^{23}$

Studies evaluating the verbal and phonological (F, A and S) fluency of adults reported no changes in cognitive function. ${ }^{7,10,24}$ The current study found no significant difference in verbal fluency performance between patients and controls. However, the migraine group showed poorer semantic verbal fluency performance (animals). There are no consistent data in the literature on semantic verbal fluency in adolescents with migraine. Quantitative disparities found in semantic and phonological verbal fluency may suggest that the two groups have significant differences in long-term memory representation and strategies used during the retrieval process. Semantic fluency seems to depend more on access to semantic memory and its integrity than on executive processes, with greater temporal lobe activation. In phonological fluency, the process of searching requires the creation of non-habitual strategies based on lexical representation, also with greater frontal lobe activation. ${ }^{25,26}$

In a cohort study assessing cognitive and academic performance in patients aged 3 to 26 , subjects with migraine were slightly, but significantly impaired in comparison to individuals with tension type headache and headache-free controls. ${ }^{18}$ The tests used in this study measured verbal ability (especially language reception) in patients aging from 3 to 13 years, regardless of the existence of any headache history, medication use, severity, or duration of episode. The association between migraine and verbal functioning also appeared to impact later academic performance.

The current study has several limitations, including its cross-sectional design and small sample size. The restrictive study inclusion criteria, i.e. lack of any psychiatric disorder and not to be under prophylactic treatment, partly explain the study numbers, and reflect the challenges of recruiting such patients. The study is clinic-based where patients were drawn from a referral center where more severe or disabling cases are usually followed. Therefore, the current findings must be viewed with caution as they do not necessarily reflect the cognitive status of patients in the community or individuals with milder forms of migraine. ${ }^{5,6}$ Also, the aforementioned findings have frequently been observed in other neurological conditions and do not seem to be specific to migraine. Future studies involving larger samples and enrollment of subjects from the community are warranted to overcome these limitations. In future studies, it is of paramount importance to evaluate whether cognitive changes identified impact school performance and/ or academic achievement.

In conclusion, the current results suggest that children and teenagers with migraine may exhibit cognitive symptoms. As similar changes are reported in adult patients with migraine, ${ }^{8,27,28}$ it remains to be established whether cognitive impairment persists throughout life and/or re-emerges later.

Support. This work was partially supported by CAPES, $\mathrm{CNPq}$ and Fapemig.

Acknowledgements. We would like to thank all the participants and their families for their collaboration in the study. We would also like to thank João Vieira Monteiro de Barros for revising the manuscript, as well as the Neurology Service of the Federal University of Minas Gerais, CNPq, and FAPEMIG for all their support on the research project.

Author contribution. MACS and ALT designed the study protocol. MACS, RSG, ALT were responsible for data collection. MACS, ACAP, and LCS performed data analysis and interpretation. MACS and ACAP wrote the first draft of the manuscript that was carefully revised and approved by all authors. 


\section{REFERENCES}

1. Lagman-Bartolome AM, Lay C. Pediatric migraine variants: a review of epidemiology, diagnosis, treatment, and outcome. Curr Neurol Neurosci Rep 2015;15:34

2. Wöber-Bingöl C. Epidemiology of migraine and headache in children and adolescents. Curr Pain Headache Rep 2013;17:341.

3. Barea L, Tannhauser M, Rotta N. An epidemiologic study of headache among children and adolescents of southern Brazil. Cephalalgia 1996; 16:545-549.

4. Araújo CM, Barbosa IG, Lemos S, Domingues RB, Teixeira AL. Cognitive impairment in migraine. Dement Neuropsychol 2012;6:74-79.

5. Suhr JA, Seng EK. Neuropsychological functioning in migraine: clinical and research implications. Cephalalgia 2012;32:39-54.

6. Rist PM, Kurth T. Migraine and cognitive decline: a topical review. Headache 2013;53:589-598.

7. Le Pira F, Zappala G, Giuffrida S, et al. Memory disturbances in migraine with and without aura: a strategy problem? Cephalalgia 2000;20: 475-478.

8. Calandre E, Bembibre J, Arnedo M, Becerra D. Cognitive disturbances and regional cerebral blood flow abnormalities in migraine patients: their relationship with the clinical manifestations of the illness. Cephalalgia 2002;22:291-302.

9. Schmitz N, Arkink E, Mulder M, et al. Frontal lobe structure and executive function in migraine patients. Neurosci Lett 2008;440:92-96.

10. Le Pira F, Lanaia F, Zappala G, et al. Relationship between clinical variables and cognitive performances in migraineurs with and without aura. Funct Neurol 2004:19:101-106.

11. Leijdekkers M, Passchier J, Goudswaard P, Menges L, Orlebeke J. Migraine patients cognitively impaired? Headache 1990;30:352-358.

12. Pearson A, Chronicle E, Maylor E, Bruce L. Cognitive function is not impaired in people with a long history of migraine: a blinded study. Cephalalgia 2006;26:74-80.

13. D'Andrea G, Nertempi P, Milone F, Joseph R, Cananzi A. Personality and memory in childhood migraine. Cephalalgia 1989;9:25-28.

14. Villa T, Correa Moutran A, Sobirai Diaz L, et a. Visual attention in children with migraine: a controlled comparative study. Cephalalgia 2009; 29:631-634.
15. Rocha-Filho PA, Santos PV. Headaches, quality of life, and academic performance in schoolchildren and adolescents. Headache 2014;54 1194-202.

16. Headache Classification Subcommittee of the International Headache Society. The international classification of headache disorders. $2^{\text {nd }}$ Edition. Cephalalgia 2004;24:1-149.

17. Riva D, Aggio F, Vago C, et al. Cognitive and behavioral effects of migraine in childhood and adolescence. Cephalalgia 2006;26:596-603.

18. Waldie K, Hausmann M, Milne B, Poulton R. Migraine and cognitive function: A life-course study. Neurology 2002;59:904-908.

19. Haverkamp F, Honscheid A, Muller-Sinik K. Cognitive development in children with migraine and their healthy unaffected siblings. Headache 2002;42:776-779.

20. O'Bryant S, Marcus D, Rains J, Penzien D. The neuropsychology of recurrent headache. Headache 2006;46:1364-1376.

21. Kruit M, van Buchem M, Launer L, Terwindt G, Ferrari M. Migraine is associated with an increased risk of deep white matter lesions, subclinical posterior circulation infarcts and brain iron accumulation: the population-based MRI CAMERA study. Cephalalgia 2010;30:129-136.

22. Porter A, Gladstone J, Dodick D. Migraine and white matter hyperintensities. Curr Pain Headache Rep 2005;9:289-93.

23. Akerman S, Goadsby P. Dopamine and migraine: biology and clinical implications. Cephalalgia 2007;27:1308-1314

24. Camarda C, Monastero R, Pipia C, Recca D, Camarda R. Interictal executive dysfunction in migraineurs without aura: relationship with duration and intensity of attacks. Cephalalgia 2007;27:1094-1100.

25. Azuma T. Working Memory and Perseveration in Verbal Fluency. Neuropsychology 2004;18:69-77.

26. Baldo J, Schwartz S, Wilkins D, Dronkers N. Role of frontal versus temporal cortex in verbal fluency as revealed by voxel-based lesion symptom mapping. J Int Neuropsychol Soc 2006;12:896-900.

27. Hooker W, Raskin N. Neuropsychologic alterations in classic and common migraine. Arch Neurol 1986;43:709-712.

28. Meyer J, Thornby J, Crawford K, Rauch G. Reversible cognitive decline accompanies migraine and cluster headaches. Headache 2000;40:638-646. 